\title{
The Relationship of Stressors and Stress on Injury Incident of Construction Workers in Penang
}

\author{
Khairul Ammar Muhd Ali ${ }^{1, a}$, Muhamad Arif Arshad ${ }^{2}$, Amalina Amirah Abu Bakar ${ }^{1}$ and Nor Janna \\ Tammy ${ }^{1}$ \\ ${ }^{1}$ Fakulti Kejuruteraan Awam, Universiti Teknologi Mara, 13500 Permatang Pauh, Pulau Pinang, Malaysia \\ ${ }^{2}$ Gaintrend Sdn Bhd, Taman Perindustrian Beringin, 14000 Bukit Tengah, Pulau Pinang, Malaysia
}

\begin{abstract}
Construction Workers (CWs) are the main source of manpower that is necessary to every construction project. Non conducive and hazardous working environment at construction site will affect the physiological health of the construction labour. This study is conducted to explore the impact of job stress and emotional stress to the CWs that potentially lead to injuries incident in Penang. Twelve stressors were identified through factor analysis. Then, the stressors are classified into five main categories. Questionnaires were developed according to the stressstressor relationship. The correlation between factors of injury incident (stressor) and stress shows that lack of autonomy and inappropriate safety equipment lead to the emotional stress among the CWs with 0.287 and 0.204 respectively. In addition, poor physical environment causes the job stress among CWs with the correlation of 0.270 .
\end{abstract}

\section{Introduction}

Standard Operation Procedure (SOP) of work is a guideline used to control quality of product or services given by the workers. Department of Occupational Safety and Health Malaysia (DOSH) investigates that accidental events in construction sector are the third highest compared to factory and farming sector for the total accident in Malaysia. In 2013, the construction industry is the highest number of death among the other industries which contributes about $37.5 \%$ or 69 deaths from total death of 185 deaths [1]. This study investigated the relationship type of stress and injuries incident (stressor) among construction workers in Penang. Therefore, by identifying which stressor gave high impact to the type of stress, the superiors of the construction project especially those who are working directly with the construction labour could help them to improve the working environment.

\section{Construction Accident}

According to Occupational Safety and Health Association (OSHA) Europe, construction workers are easier to get involved in an accident two times and more potential to face death three times compared to workers in other industries [2]. In Malaysia, DOSH categorised the construction accident due to the effects after the accident happened which are death, non-permanent disability and permanent disability. From the same source, the death category is the most happened in Malaysia construction

\footnotetext{
${ }^{a}$ Corresponding author : khairulammar.ali@ppinang.uitm.edu.my
} 
industries [1]. The most construction of fatal accidents in 2007 and 2008 were fall down from high level, slip and stuck by objects [4].

\subsection{Physiological stress contribute to construction accident}

Physiological stress positively was a factor to an accident among Hong Kong construction workers [12]. Construction workers are more 1.7 times more susceptible to have psychological health problems like psychiatric disorders included stress-related problems than other industries workers [5]. Too much work load, period duties, unfair reward, way of communication between labour and foreman and lack of skills in completing task are the causes of stress problems to construction workers [6]. Stresses problems among workers will affect the awareness and compliance of safety and health issues and will be one of the factors contributing to accidents in construction site.

\subsection{Effects of construction accident}

The operations of construction project need to be stopped immediately to give space for the authorities to do the investigation on site, and as a result, the project will be delayed from the time line. Since the project is delayed, the contractor needs to pay penalty to the developer as a compensation of delayed time. Secondly, it will affect the reputation of a company. Since the accident was recorded by the authority especially related to fatal tragedies, the company will get bad reputation, perception and trust from people and workers for the next project. Thirdly, the effect of accident will impact labours'psychology. This problem will affect to either the labour, victim of the accidental event or others around him/her. Labours will face trauma and stress to do work in construction site, thus will produce awful quality to the production. Hence, accident in construction site also gives negative impact to employer, employee and client [7].

\subsection{Construction workers in Malaysia}

According to Department of Statistic Malaysia (DOSM), amount of labour in Malaysia construction sector is divided into two groups which are the citizens (93759 people) and non-citizens (181,730 people) [8]. Malaysian Investment Development Authority (MIDA) stated that only 12 countries are allowed to work in Malaysia construction industries which are known as Indonesia, Cambodia, Nepal, Myanmar, Laos, Vietnam, Philippines (male only), Pakistan, Sri Lanka, Thailand, Turkmenistan, Uzbekistan and Kazakhstan [9]. Most non-citizen construction labours have different cultures and languages to communicate compared to Malaysian. While having difficulties to understand between site supervisor and general workers, this will cause error information as well as in action. Thus, the situation can contribute stress among workers and stress may cause an accident during the construction.

\subsection{Construction in Penang}

According to CIDB Malaysia, from 2012 to 2014, Penang ranked at number 5 out of 14 states with the highest numbers of construction after Johor, Selangor, Wilayah Persekutuan and Perak [10]. DOSH recorded that from 2012 until February 2014, the total number of constructions in Penang was 1138 with 376 numbers of accidents [11]. The percentage of number of accident to number of construction in Penang is $33.04 \%$. 6.17\% for Perak where the number of constructions were 3016 and number of accidents are 186. Selangor had two times higher number of constructions compared to Penang, but the percentage of construction accident was low. Hence, there is a need to study the reasons (stressor) that contributed to a high number of construction accidents in Penang. 


\subsection{Stressor}

Stressor are factors why physiology stress happened among human. The factors of stressor might differ depending on types of industries as well as the difficulties of a job, number of task, environment and many more. Table 1 shows five groups of stressor in construction industries stated by Leung, 2010 [12].

Table 1. Group of stressor and factor contribute to stressor.

\begin{tabular}{|l|l|}
\hline \multirow{4}{*}{ Group of stressor } & Factors of stressor \\
\hline \multirow{3}{*}{ ) Task Stressor } & 1. Work overload \\
\cline { 2 - 2 } & 2. Role Ambiguity \\
\cline { 2 - 2 } & 3. Lack of autonomy \\
\hline \multirow{2}{*}{ 2) Organizational Stressor } & 4. Unfair reward \& treatment \\
\cline { 2 - 2 } & 5. Inappropriate safety equipment \\
\hline \multirow{2}{*}{ 3) Personal Stressor } & 6. Type A behaviour \\
\hline \multirow{3}{*}{ 4) Interpersonal Stressor } & 7. Optimism \\
\hline \multirow{2}{*}{ 5) Physical Stressor. } & 8. Inter-role conflict \\
\cline { 2 - 2 } & 9. Poor workgroup relationship \\
\cline { 2 - 2 } & 10. Lack of feedback \\
\hline & 11. Poor physical environment \\
\cline { 2 - 2 } & 12. Unsafe environment \\
\hline
\end{tabular}

\subsection{Stress}

Stress is a force or pressure to something in a society and stress can lead to lack of performance [13]. Today, people have started to become aware of "human stress" especially the stress experienced by construction industry personnel. Stress can be divided into two types which are job stress and emotional stress [12].

\section{Methodology}

\subsection{Stressor identification}

The identification of factors that contributed to stress among construction labours is grouped into five main categories as shown in Figure 1.



Figure 1. Process of stress-stressor relationship. 
An injury incident may happen due to stress either job stress or emotional stress. The factors which are causing stress can be developed by these five groups of stressor as shown in Figure 1. This process of stress-stressor relationship is adopted form Leung, 2010 which previously studied on construction workers'accidents in Hong Kong [12]. Emotional scale is a compilation of 13 questions used to measure the level stress of construction labour due to emotional problems [14]. Out of 13 questions, only 4 were used in this study. Job stress scale developed by Gmelch in 1982 was used to measure the actual and expected abilities work need to be completed by labour. However, this study adopted the improvised job stress scale which in line with construction work scope produced by Leung, 2010 [12]. For the information of injuries, the numbers of accident happened in the same particular project was collected and the data was used to project the potential future incident. The period of accidents occurred in the particular project is collected between the previous two years of time since it is considered still as a short reference period [15].

\subsection{Questionnaire}

The questionnaires were developed according to the stress-stressor relationship and the scales mentioned earlier. The respondents of this questionnaire were only non-executive workers since these people conquered the construction sites in Malaysia as labours and are able to be involved in construction accidents [4]. The seven points Likert scale were used as a scale agreement which ranging from 1 (strongly disagree) to 7 (strongly agree). The questionnaires were given to CWs in Penang construction areas.

\subsection{Data analysis}

Analyses involved in this study are reliability analysis, correlation analysis and multiple linear regressions. Reliability analysis is used to find either the question is related to the objectives or not. This method is a common method used as an indicator to internal consistency. Correlation analysis is a statistical method used to determine whether a linear or curvilinear relationship between variance exists [16]. This study used this equation to determine linear relationship between of stressor, stress and injury incident. Multiple Linear Regressions analysis is applied to find the relationship between two variables that continue from correlation analysis process. The possibilities can be positive linear relationship, negative linear relationship, curvilinear relationship or no discernible relationship [16]. In this study, the relationships of stressor-stress and stress-injury incident were revealed.

\section{Discussion}

The alpha Cronbach's value gained from Reliability analysis shows that the job stress and emotional stress is 0.65 and 0.68 respectively. According to Bluman, 2005, the acceptable value is more than 0.6 [16]. Hence, the questionnaires are valid to be used in this research. The Pearson's correlation analysis was used to determine linear relationship between of stressor, stress and injury incident. The result indicates that the highest correlation between various stressor and job stress is poor physical environment with correlation value of 0.270 . The highest correlation between various stressor and emotional stress is lack of autonomy with correlation value of 0.287 . Moreover, inappropriate safety equipment is the second highest stressor with value of correlation recorded as 0.204 . The Multiple Regression Analysis method is used to discover the interdependent relationship between two type of stress, various stressor and injuries incident based on previous correlation analysis. In addition, to prove that the job stress has no relationship to the cause of accident in construction site, the curvilinear interdependent relationship between construction workers injuries incident and two types of stresses were developed. The curvilinear results are shown in Figure 2. 


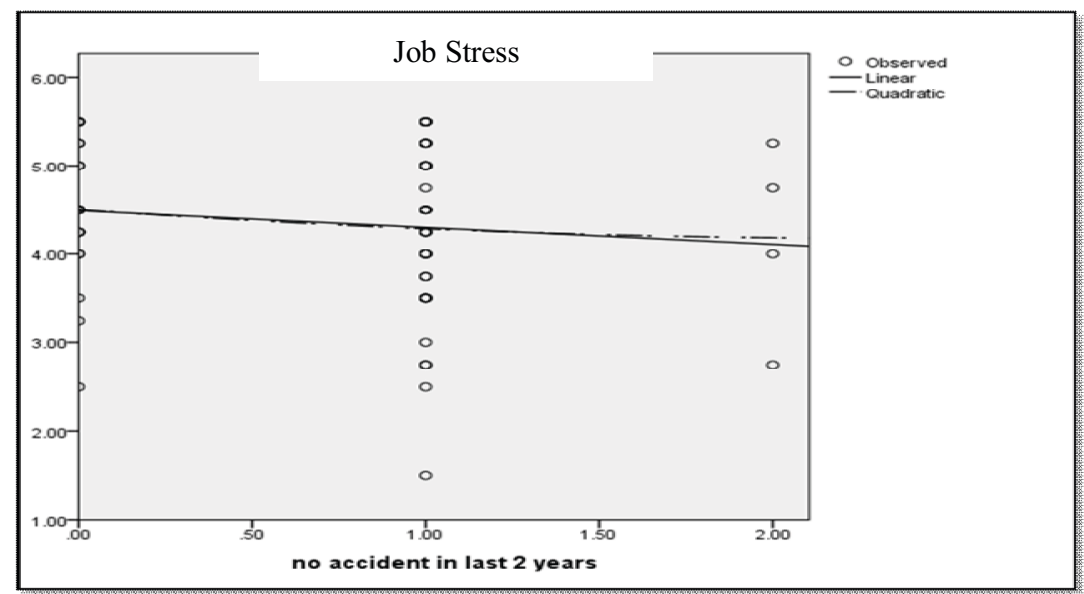

(a)

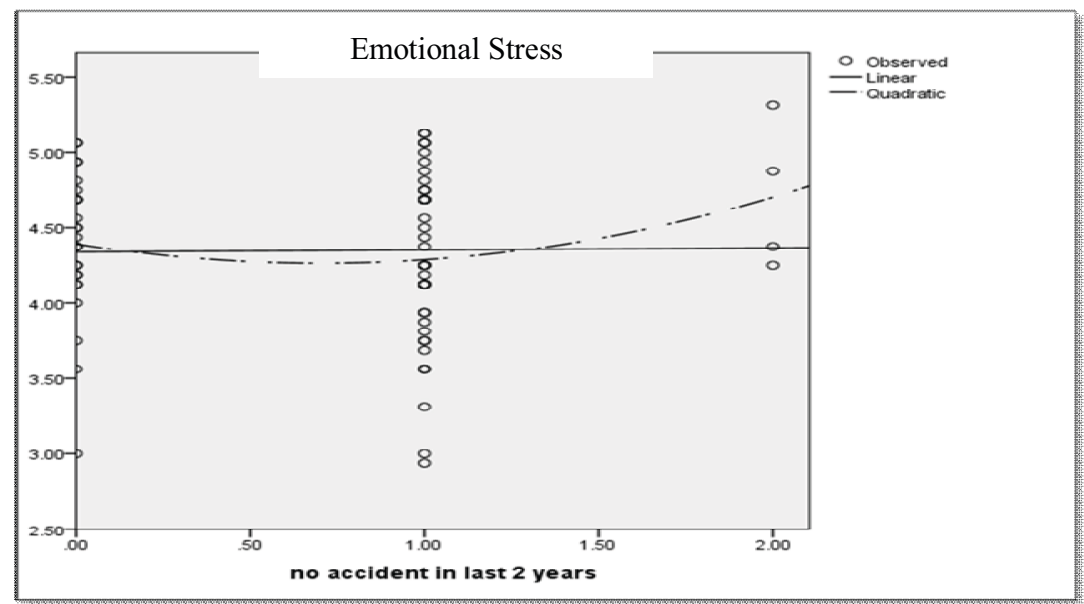

(b)

Figure 2. Curvilinear relationship between number of accident and (a) job and (b) emotional stress.

These curvilinear shows that the job stress resulted in negative curvilinear relationship compared to emotional stress that resulted in positive curvilinear relationship. A positive curvilinear shows that emotional stress could lead to potential of injuries incident to the construction workers. Based on the analysis, the relationship of stressor-stress-injuries incident is simplified statistically as shown in Figure 3.

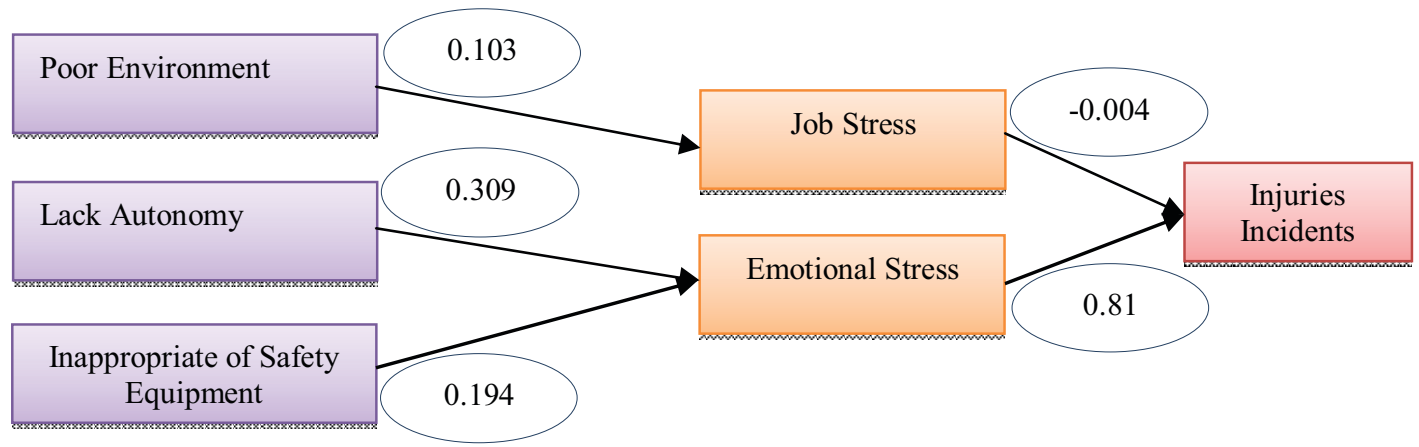

Figure 3. Integrated stressor-stress-injury incident statistical model for construction workers. 
Since it is identified that the emotional stress could affect the construction workers; it is a need to reduce numbers of accident. Murray et al, 1997 stated that people who suffer from emotional stress may act to poor safety behaviour like less precautions and focus to safety compliance [17]. Hence, those people may face high potential to get injury incidents.

\section{Conclusion}

In conclusion, from this study, the factors that contributed to emotional stress among labours are lack of autonomy and inappropriate of safety equipment used in construction project while the factor that affect job stress is a poor physical environment of construction site. Emotional stress has positive relationship with the injury incidents of construction workers. For the job stress, there is no relationship with the injury incidents. However, statistical significance does not necessarily mean practical significance and lack of significance does not necessarily means that the null hypothesis is true [16].

\section{References}

[1] Department of Occupational Safety and Health, Occupational accidents statistics by sector until December 2013, (2013). <retrieve from http://www.dosh.gov.my>

[2] European Agency for Safety and Health at Work, Safety and health at work: How dangerous is construction, (2014). <retrieve from https://osha.europa.eu>

[3] S. Hide, S. Atkinson, T.C. Pavitt, R. Haslam, A.G. Gibb and D.E. Gyi, Causal factors in construction accidents, Health and Safety Executive, (2003).

[4] D.N.M.A Abdullah and G.C.M. Wern, An analysis of accidents statistics in Malaysian construction sector. International Proceedings of Economics Development and Research, 3, (2011).

[5] J.S Peterson and C. Zwerling, Comparison of health outcomes among older construction and blue-collar employees in the United States, American Journal of Industrial Medicine, 34, 280287, (1998).

[6] R. Choudhry, D. Fang and S. Ahmed, Safety management in construction: Best Practices in Hong Kong, J. Prof. Issues Eng. Educ. Pract., 134(1), 20-32, (2008).

[7] S.X. Zeng, H.C. Wang and C.M. Tam, A survey of construction site safety in China, 243-248, (2001).

[8] Department of Statistic Malaysia, Population and vital statistics, (2012). <retrieve from http://www.statistics.gov.my>

[9] Malaysian Investment Development Authority, Employment of foreign workers, (2014). <retrieve from http://www.mida.gov.my>

[10]Construction Industrial Develepment Board Malaysia, Buletin 2014, (2014). <retrieve from https://www.cidb.gov.my>

[11]Department of Occupational Safety and Health, Occupational accidents statistics by state until December 2013, (2013). <retrieve from http://www.dosh.gov.my>

[12]M. Leung, Y. Chan and K. Yuen, Impacts of stressors and stress on the injury incidents of construction workers in Hong Kong, (2010).

[13]U. Lundberg, Stress, subjective and objective health, International Journal of Social Welfare, 15(1), 41-48, (2006).

[14]C. Maslach, S.E. Jackson and M.P. Leiter, Maslach Burnout Inventory, (1986).

[15]D.D. Landen and S. Hendricks, Effect of recall on reporting of at work injuries, Public health Reports, 110(3), 350, (1995).

[16]A.G. Bluman, Elementary Statistics, A Step by Step Approach, McGraw-Hill, (2004).

[17]C.J.L Murray and A. Lopez, Global Health Statistics, Harvard University Press, Cambridge, (1996). 